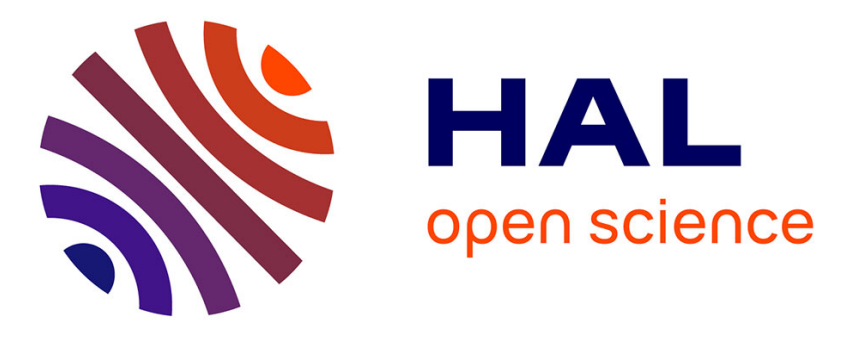

\title{
Pavement Design for Curved Road Sections: Fatigue Performance of Interfaces and Longitudinal Top-down Cracking in Multilayered Pavements
}

Christophe Petit, Malick Diakhaté, Anne Millien, Annabelle

Phelipot-Mardelé, Bertrand Pouteau

\section{To cite this version:}

Christophe Petit, Malick Diakhaté, Anne Millien, Annabelle Phelipot-Mardelé, Bertrand Pouteau. Pavement Design for Curved Road Sections: Fatigue Performance of Interfaces and Longitudinal Top-down Cracking in Multilayered Pavements. Road Materials and Pavement Design, 2009, 10 (3), pp.609-624. 10.3166/rmpd.10.609-624 . hal-00521907

\section{HAL Id: hal-00521907 \\ https://hal.science/hal-00521907}

Submitted on 28 Sep 2010

HAL is a multi-disciplinary open access archive for the deposit and dissemination of scientific research documents, whether they are published or not. The documents may come from teaching and research institutions in France or abroad, or from public or private research centers.
L'archive ouverte pluridisciplinaire HAL, est destinée au dépôt et à la diffusion de documents scientifiques de niveau recherche, publiés ou non, émanant des établissements d'enseignement et de recherche français ou étrangers, des laboratoires publics ou privés. 


\title{
Pavement Design for Curved Road Sections
}

\section{Fatigue performance of interfaces and longitudinal top- down cracking in multilayered pavements}

\author{
Christophe Petit* - Malick Diakhaté* — Anne Millien* - \\ Annabelle Phelipot-Mardelé* — Bertrand Pouteau** \\ * Université de Limoges, Laboratoire GEMH-GCD \\ Centre Universitaire de Génie Civil \\ Boulevard Jacques Derche \\ F-19300 Egletons \\ \{christophe.petit; malick.diakhate; anne.millien; phelipot\}@unilim.fr \\ ** EUROVIA, Centre de Recherche de Mérignac \\ 22 rue Thierry Sabine \\ F-33703 Mérignac Cedex \\ bpouteau@eurovia.com
}

\begin{abstract}
This paper focuses on damage processes other than the main one observed and studied in pavement design. Previous research has targeted the experimental fatigue performance of tack coats. The French Pavement Design method has been chosen herein to illustrate how interface fatigue performance can lead to improved design, especially when pavements are subjected to repeated horizontal loadings. In a curved pavement section, longitudinal top-down cracking is observed, and this damage process may also be taken into account during the design approach. A $3 D$ finite element model has been derived to assess pavement lifetime. In conclusion, it is proposed to include the fatigue performance of interfaces when designing pavements with horizontal loadings and thin surface layers.
\end{abstract}

KEYWORDS: Pavement design, Fatigue, Interface, Finite element, Top-down cracking, Lifetime.

Road Materials and Pavements Design. Volume X - No X/2009, pages 1 to 16 


\section{Introduction}

A new concept is being introduced here, based on the recent work devoted to experimental interface fatigue performance (Diakhaté, 2007,2008; Pouteau, 2008), in association with a new type of damage (top-down longitudinal cracking) observed on real pavements subjected to significant horizontal loadings over thin surface overlays. These important findings have led to identifying a primary damage different from that given by any other pavement design method. The goal of this paper is to show that in certain pavement sections exposed to significant and repeated horizontal loadings, specific failure modes need to be included in the pavement design approach. It is thus proposed for the pavement designer to ensure verification of both interface fatigue and longitudinal top-down cracking. In its present form, the design method merely includes laboratory experimentation and does not take into account any field evaluations for either the interface or top-down fatigue.

\section{Pavement finite element analysis}

This section of the paper is devoted to a pavement fatigue simulation that includes the fatigue damage of both layers and interfaces. Two models are presented: according to the first, the pavement is studied under normal cyclic loading conditions; whereas the second model studies a curved road section in order to heavily load the pavement with normal and transverse cyclic loadings. This second situation is not conventional and has thus not been included in the French Pavement Design method (LCPC, SETRA, 1998), even though a specific and relevant damage process has been observed in the field. Moreover, this second simulation has been chosen to illustrate that under such conditions, top-down cracking or interface fatigue can be extremely significant and capable of constituting the main damage process. Romanoschi (2001) demonstrated that critical horizontal strains may lead to surface cracking in the presence of horizontal loading, and this phenomenon also depends on interface performance. The research reported herein has confirmed these effects and proposes computing pavement lifetime by introducing the appropriate fatigue laws. The numerical work has been conducted by means of the finite element method using French software (Cast3M, 2003); it should be pointed out however that this computation could have been performed with other methods as well (Caron, 2006; Burmister, 1945).

\subsection{Presentation of the pavement structures}

The studied pavement is of a current design and composed of Hot Mix Asphalt (HMA) layers; its characteristics and elastic properties are given in Tables 1-3.

These three pavement structures have been chosen in order to examine various traffic levels and lifetimes (according to the French Pavement Design code). These 
structures are respectively: a flexible pavement for low traffic loads, and both a semi-rigid asphalt pavement and rigid asphalt pavement for regular loads. Only the layer thicknesses actually vary according to level of traffic and lifetime. In Table 4, $\mathrm{TCi}_{\mathrm{y}}$ represents the Traffic Class number "I" for a lifetime of "y" years (where y = 20 or 30 Standard French Lifetimes). PF2 is the French soil bearing class, here it correspond to soil stiffness modulus equal to $50 \mathrm{MPa}$.

Table 1: Pavement dimension and properties for the GB3/GB3/PF2-TC3 ${ }_{20}$ materials

\begin{tabular}{|c|l|c|c|c|c|}
\hline Pavement & \multicolumn{1}{|c|}{ Layers } & $\begin{array}{c}\text { Material } \\
\text { code }\end{array}$ & Thickness & E $\left(15^{\circ} \mathrm{C}, 10 \mathrm{~Hz}\right)$ & $v$ \\
\hline \multirow{2}{*}{$\begin{array}{c}\text { French } \\
\text { design code }\end{array}$} & Surface layer & BBSG & $60 \mathrm{~mm}$ & $5,400 \mathrm{MPa}$ & 0.35 \\
\cline { 2 - 6 } VRNS no. 2 & Base layer & GB3 & $80 \mathrm{~mm}$ & $9,300 \mathrm{MPa}$ & 0.35 \\
\cline { 2 - 6 } & Foundation layer & GB3 & $80 \mathrm{~mm}$ & $9,300 \mathrm{MPa}$ & 0.35 \\
\hline
\end{tabular}

Table 2: Pavement dimension and properties for the GB3/GB3/PF2-TC5 20 materials

\begin{tabular}{|c|l|c|c|c|c|}
\hline Pavement & \multicolumn{1}{|c|}{ Layers } & $\begin{array}{c}\text { Material } \\
\text { code }\end{array}$ & Thickness & E $\left(15^{\circ} \mathrm{C}, 10 \mathrm{~Hz}\right)$ & $v$ \\
\hline \multirow{2}{*}{$\begin{array}{c}\text { French } \\
\text { design code } \\
\text { VRNS no. } 2\end{array}$} & Surface layer & BBSG & $80 \mathrm{~mm}$ & $5,400 \mathrm{MPa}$ & 0.35 \\
\cline { 2 - 6 } & Base layer & GB3 & $100 \mathrm{~mm}$ & $9,300 \mathrm{MPa}$ & 0.35 \\
\cline { 2 - 6 } & Foundation layer & GB3 & $110 \mathrm{~mm}$ & $9,300 \mathrm{MPa}$ & 0.35 \\
\hline
\end{tabular}

Table 3: Pavement dimension and properties for the GB3/GB3/PF2-TC5 $5_{30}$ materials

\begin{tabular}{|c|l|c|c|c|c|}
\hline Pavement & \multicolumn{1}{|c|}{ Layers } & $\begin{array}{c}\text { Material } \\
\text { code }\end{array}$ & Thickness & E $\left(15^{\circ} \mathrm{C}, 10 \mathrm{~Hz}\right)$ & $v$ \\
\hline \multirow{2}{*}{$\begin{array}{c}\text { French } \\
\text { design code }\end{array}$} & Surface layer & BBSG & $80 \mathrm{~mm}$ & $5,400 \mathrm{MPa}$ & 0.35 \\
\cline { 2 - 6 } VRNS no. 2 & Base layer & GB3 & $130 \mathrm{~mm}$ & $9,300 \mathrm{MPa}$ & 0.35 \\
\cline { 2 - 6 } & Foundation layer & GB3 & $130 \mathrm{~mm}$ & $9,300 \mathrm{MPa}$ & 0.35 \\
\hline
\end{tabular}

Table 4: French pavement design: Traffic class (lifetime)

\begin{tabular}{|c|c|c|c|c|}
\hline \multirow[b]{2}{*}{ Pavement structure } & \multicolumn{3}{|c|}{ Soil layer } & \multirow{2}{*}{$\begin{array}{l}\text { Number of standard } \\
\text { axles [LCP 98] }\end{array}$} \\
\hline & $\begin{array}{l}\text { Bearing } \\
\text { class }\end{array}$ & E & $v$ & \\
\hline GB3/GB3/PF2-TC3 20 & \multirow{3}{*}{ PF2 } & \multirow{3}{*}{$50 \mathrm{MPa}$} & \multirow{3}{*}{0.35} & $0.210^{6}<\mathrm{NE}<0.610^{6}$ \\
\hline GB3/GB3/PF2-TC5 20 & & & & $1.310^{6}<\mathrm{NE}<3.210^{6}$ \\
\hline GB3/GB3/PF2-TC5 $_{30}$ & & & & $4.510^{6}<\mathrm{NE}<11.310^{6}$ \\
\hline
\end{tabular}

This study incorporates both types of loadings: a vertical loading in the current road section, and a horizontal loading for curved roads. The superposition principle 
will be applied next. In each case, it is possible to analyze the mechanical field within just one quarter of the finite element mesh by use of symmetry planes (see Fig. 1). Romanoschi (2001) built two finite element meshes: the first is a quartermesh with two symmetry planes for a dual-axle vertical loading, while the second is a half-mesh for horizontal loadings. In this paper, only the quarter-mesh has been used given the presence of two symmetry planes for vertical loading along with one symmetry plane and one antisymmetry plane for horizontal loading conditions. The superposition principle has been applied in order to obtain a mechanical field since both the horizontal and vertical loads act simultaneously. Le loading area is a rectangular as shown on figure 1 .

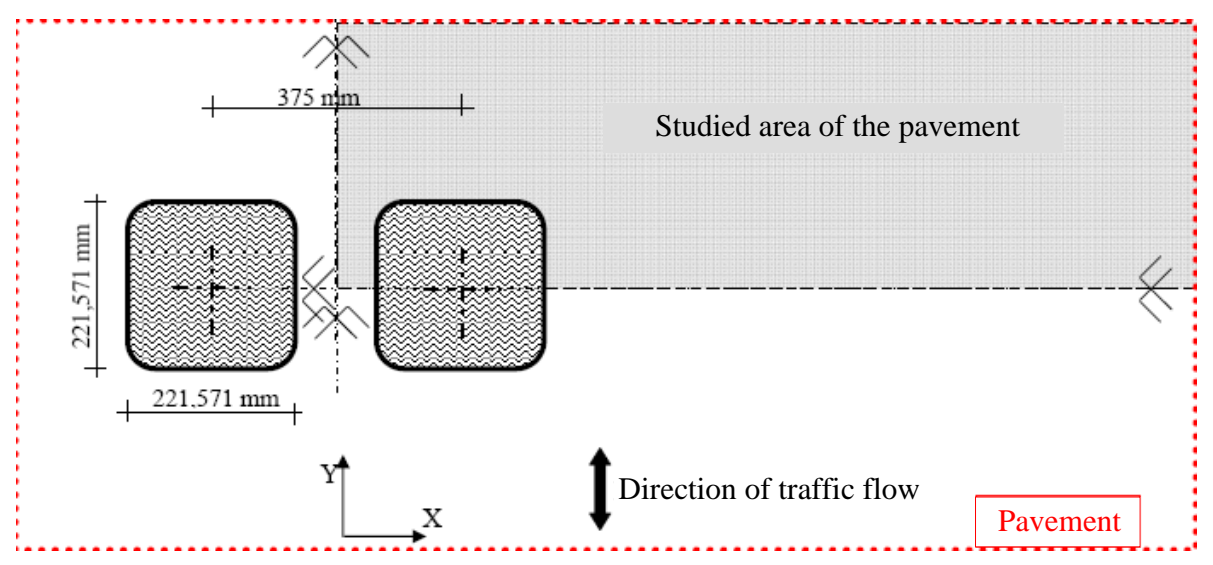

Figure 1: Tire contact area of the dual-axle traffic load

For normal loading configurations, symmetry boundary conditions may be introduced for the $\mathrm{X}-\mathrm{Z}$ plane (i.e. with zero $\mathrm{Y}$ displacements) and the $\mathrm{Y}-\mathrm{Z}$ plane (zero $\mathrm{X}$ displacements). Moreover, for horizontal loadings, the antisymmetry condition can be applied for the Y-Z plane (zero Z displacements) (Fig. 2).
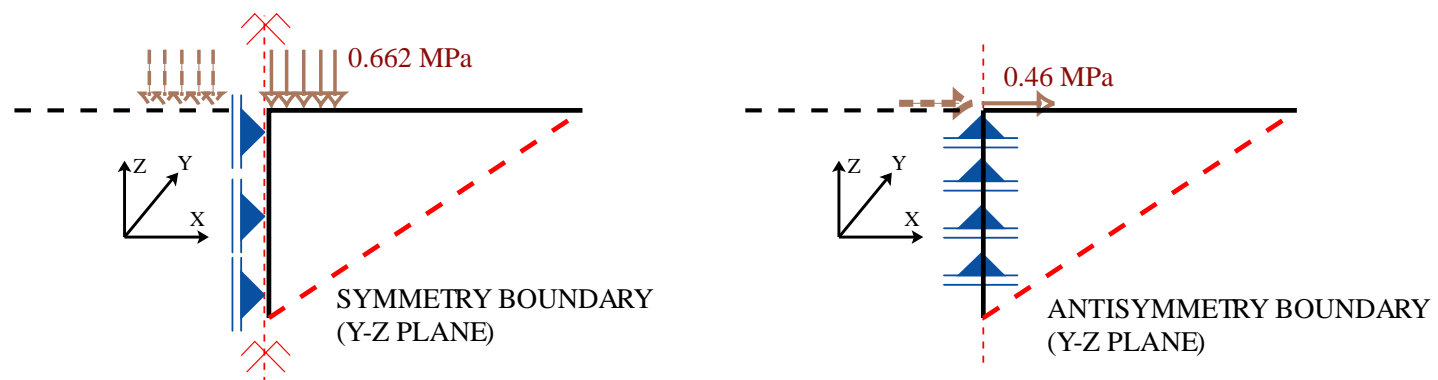

Figure 2: Symmetry and antisymmetry boundary conditions 


\subsection{The one-quarter Finite Element mesh}

This mesh has been optimized in order to generate sufficiently accurate stress and strain fields in areas with a higher level of strain field (located close to the tire pressure contact area and at the interface in such areas). This mesh contains 25,900 cubic elements (8-node elements) and a total of 28,728 nodes (Fig. 3). The right part of figure 3 show a zoom located in the left part. Different colors for each layers are used. In this figure and in agreement with figure 1, the loading area is rectangular 110.79 x $221.57 \mathrm{~mm}$.

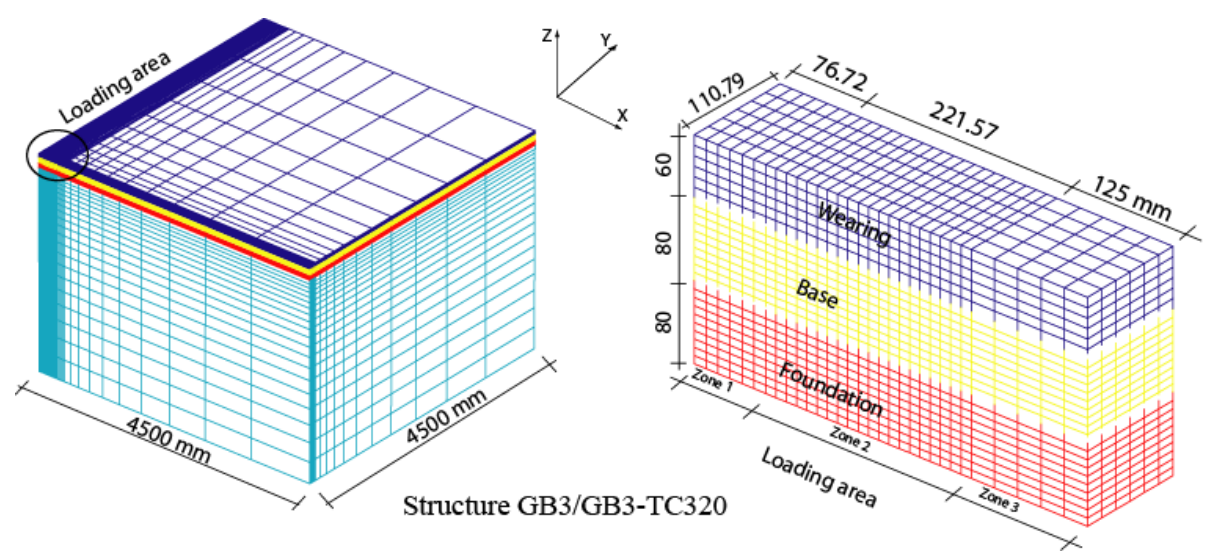

Figure 3: 3D representation of the one-quarter Finite Element mesh

\subsection{Horizontal loading}

Vertical loading is defined in every pavement design method, including the French standard method. The $65-\mathrm{kN}$ dual-wheel axle is assumed, and this results in $0.662 \mathrm{MPa}$ on the tire contact surface area (LCPC, 1998). The present work calls for adding a horizontal loading due to centrifugal forces for the curved road model. By considering a standard truck in a curve with radius $\mathrm{R}$, speed $\mathrm{V}$ and weight $\mathrm{M}$, a centrifugal force can be assumed and described by the following relation:

$$
F=\frac{M \cdot V^{2}}{R}
$$

For this study, we set $\mathrm{R}=10 \mathrm{~m}, \mathrm{~V}=30 \mathrm{~km} / \mathrm{hr}$ and $\mathrm{M}=65 \mathrm{kN}$; the above equation assumes a symmetric loading on both wheels positioned on the standard $130-\mathrm{kN}$ axle. For each truck traveling in the turn, a $45-\mathrm{kN}$ horizontal force is added under the assumption of uniform application over the tire contact area. The uniform 
shear stress surface equals $0.46 \mathrm{MPa}$, which corresponds to a friction coefficient $\mu=$ 0.7; this value is the same as that used by Romanoschi (2001).

\subsection{Conventional French Pavement Design (vertical loading only)}

\subsubsection{Bending fatigue}

This section will describe application of the standard design method to a current straight road section. For this particular case, it is well known that longitudinal strain is greater than transverse strain, which provides the reason why transverse crack initiation rises to the pavement surface. Let $\varepsilon_{\mathrm{t}}$ be the maximum longitudinal strain due to bending at the bottom of asphalt layers. The French standard fatigue law can then be easily introduced to calculate the lifetime NEbc (i.e. number of equivalent standard axles) by the equation:

$\varepsilon_{t} \leq \varepsilon_{6\left(10^{\circ} \mathrm{C}, 25 \mathrm{~Hz}\right)} \cdot\left(\frac{E_{\left(10^{\circ} \mathrm{C}, 10 \mathrm{~Hz}\right)}}{E_{\left(15^{\circ} \mathrm{C}, 10 \mathrm{~Hz}\right)}}\right)^{0,5} \cdot\left(\frac{N E_{b c}}{10^{6}}\right)^{b} \cdot k_{r} \cdot k_{c} \cdot k_{s}$

with:

- $\varepsilon_{6\left(10^{\circ} \mathrm{C}, 25 \mathrm{~Hz}\right)}$ : Strain level at failure after one million cycles $\left(10^{6}\right)$;

- $E_{\left(10^{\circ} \mathrm{C}, 10 \mathrm{~Hz}\right)}$ : Elastic modulus at $10^{\circ} \mathrm{C}, 10 \mathrm{~Hz}$;

- $E_{\left(15^{\circ} \mathrm{C}, 10 \mathrm{~Hz}\right)}$ : Elastic modulus at $15^{\circ} \mathrm{C}, 10 \mathrm{~Hz}$;

- $N E_{b c}$ : Number of equivalent standard axles for bottom cracking;

- $b$ : Slope of the fatigue law (in a $\log \varepsilon_{\mathrm{t}}-\log N E$ diagram);

- $k_{r}$ : Variability coefficient, i.e. a function of calculation risk and scattering factors;

- $k_{c}$ : Fitting coefficient between numerical design and field observations;

- $k_{s}$ : Coefficient for heterogeneities in soil bearing capacity.

In Equation (2), the strain level $\varepsilon_{\mathrm{t}}$ in the foundation layer along with the HMA fatigue parameters $\left(\varepsilon_{6}, \mathrm{~b}\right)$ are required (see Table 5). For a detailed description of this parameters please report to (LCPC, 1998). 
Table 5: Material fatigue parameters for the HMA specimen referred to as GB3

\begin{tabular}{|c|c|c|c|c|}
\hline Material & $\varepsilon_{6\left(10^{\circ} \mathrm{C}, 25 \mathrm{~Hz}\right)}$ & $E_{\left(10^{\circ} \mathrm{C}, 10 \mathrm{~Hz}\right)}$ & $E_{\left(15^{\circ} \mathrm{C}, 10 \mathrm{~Hz}\right)}$ & $\mathrm{b}$ \\
\hline GB3 (HMA) & $90 \cdot 10^{-6}$ & $12,300 \mathrm{MPa}$ & $9,300 \mathrm{MPa}$ & -0.2 \\
\hline
\end{tabular}

Numerical computations can be carried out using a standard elastic multilayer software, or an analytical model can also be used (Burmister, 1945). The Alize software is the standard for French Pavement Design; this package is capable of calculating the elastic response of a multilayered pavement featuring the elastic and geometric properties listed in Tables 1,2 and 3 . The obtained numerical or analytical response $\varepsilon_{t}$ is then inserted into Equation (2) to yield the lifetime $N E$. During assessment of this lifetime, the two field observation parameters $\left(k_{c}\right.$ and $\left.k_{s}\right)$ are not taken into account since no information is available on these parameters relative to either interface fatigue performance or top-down fatigue cracking. In the subsequent sections, this analysis will allow comparing pavement lifetimes specific to the various failure modes (i.e. conventional bottom cracking, interface fatigue performance, and top-down cracking).

The set of numerical computations of lifetimes NEbc (where bc stands for bottom cracking) are presented in Table 6. Note that under such loading conditions, the maximum strain is found at the asphalt layer bottom.

Table 6: Cumulative number of equivalent standard axles (NEbc) for bottom layer fatigue

\begin{tabular}{|c|c|c|c|c|c|}
\hline Pavement structure & Lifetime & Risk & Strain $\left(\varepsilon_{t}\right)$ & $\mathrm{k}_{\mathrm{r}}$ & $\begin{array}{l}\text { Number of equivalent } \\
\text { standard axles }(N E b c)\end{array}$ \\
\hline GB3/GB3/PF2-TC3 20 & \multirow{2}{*}{20 years } & $18 \%$ & $116 \cdot 10^{-6}$ & 0.847 & $0.25 \cdot 10^{6}$ \\
\hline GB3/GB3/PF2-TC5 20 & & \multirow{2}{*}{$5 \%$} & $76.5 \cdot 10^{-6}$ & \multirow{2}{*}{0.743} & $1.03 \cdot 10^{6}$ \\
\hline GB3/GB3/PF2-TC5 30 & 30 years & & $58.6 \cdot 10^{-6}$ & & $3.89 \cdot 10^{6}$ \\
\hline
\end{tabular}

\subsubsection{Shear fatigue at the interfaces}

The focus here is exclusively on interface damage; under certain conditions, thin surface layers are observed to exhibit debonding. Some recent experimental work has provided interface fatigue performance results on the tack coat (Diakhaté, 2007, 2008). Other authors have also shown interest in interface performance yet have not specifically examined interface fatigue performance (Canestrari, 2005; Tran, 2006; Granju, 2004). 
In assessing the maximum shear stress under the standard axle, a debonding risk becomes apparent at the highest (BBSG/GB3) interface. The shear stress distribution at the dual-axle location is depicted in Figure 4. The maximum stresses are found at the outside edge of each wheel. The maximum shear stress is close to $0.20 \mathrm{MPa}$ for each of the tested pavement structures. In reality, the level of shear stress depends mainly on surface layer thickness. This study must be conducted for very thin layers since a high level of shear stress is generated at the interface.

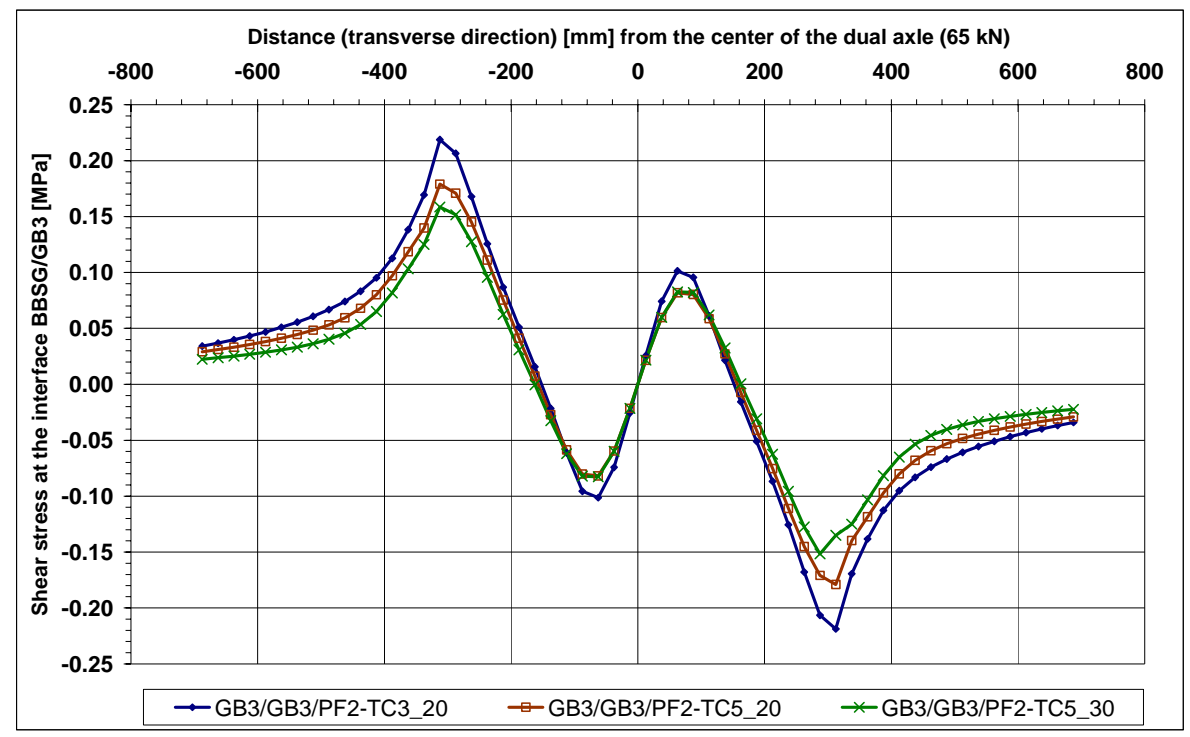

Figure 4: Shear stress distribution at the top (BBSG/GB3) interface

Previous experimental research (Diakhaté, 2008) has given rise to shearing fatigue laws, such as those indicated in Equation (3). The same relationship is derived as for bending fatigue. In Equation (3), shear fatigue parameters of the tack coat (C65B4 $-70 / 100 \mathrm{Pen}$ ) have been input at $10^{\circ} \mathrm{C}$, i.e.: $\tau_{6}=0.36 \mathrm{MPa}$, Ks $=104$ $\mathrm{MPa} / \mathrm{mm}$, and $\mathrm{b}=-0.223$, where $N E_{i}$ is the number of standard axles (lifetime) at failure, and Ks is the interface shear stiffness. Equation (3) related to shear interface fatigue is presented in the same way as Equation (2) for the bottom layer, although the field observation coefficients $\left(k_{c}\right.$ and $\left.k_{s}\right)$ have not been included. The risk parameter $\mathrm{k}_{\mathrm{r}}$ is assigned the values listed in Table 6 .

$$
\tau_{\max } \leq \tau_{6\left(10^{\circ} \mathrm{C}, 10 \mathrm{~Hz}\right)} \cdot\left(\frac{K_{S\left(10^{\circ} \mathrm{C}-10 \mathrm{~Hz}\right)}}{K_{S\left(15^{\circ} \mathrm{C}-10 \mathrm{~Hz}\right)}}\right)^{-1,697} \cdot\left(\frac{N E_{i}}{10^{6}}\right)^{-0,223} \cdot k_{r}
$$


With this fatigue law, it is now possible to assess the interface lifetime (NEi). In most current cases when the level of traffic is mainly lower, the lifetime of the interface is determined to be greater than that of the layers. For this reason, the pavement design method does not include interface fatigue performance. Once this calculation has been carried out, the need becomes obvious, for cases of heavy traffic and thin asphalt pavements, to verify interface fatigue failure and then add interface verification into the pavement design approach. Under such conditions, tack coat performance may prove to be of great importance.

Table 7: Tack Coat Lifetime (NEi) calculation

\begin{tabular}{|c|c|c|c|}
\hline Pavement structure & $\begin{array}{l}\text { Shear stress level } \\
\left(\tau_{\max }\right)\end{array}$ & $k_{\mathrm{r}}$ & $\begin{array}{l}\text { Number of standard axles at } \\
\text { interface failure (NEi) }\end{array}$ \\
\hline GB3/GB3/PF2-TC3 20 & $0.22 \mathrm{MPa}$ & 0.847 & $0.64 \cdot 10^{6}$ \\
\hline GB3/GB3/PF2-TC5 20 & $0.18 \mathrm{MPa}$ & \multirow{2}{*}{0.743} & $0.88 \cdot 10^{6}$ \\
\hline GB3/GB3/PF2-TC5 ${ }_{30}$ & $0.15 \mathrm{MPa}$ & & $1.98 \cdot 10^{6}$ \\
\hline
\end{tabular}

The focus now turns to the curved section of a road that has been subjected to a horizontal loading. It can then be evaluated whether or not the fatigue failure process remains the same.

\subsection{Special pavement section with a cyclic horizontal loading}

In this section, a superposition of the horizontal effect (0.46 MPa) will be taken into account, as shown in Figure 2. The same one-quarter mesh with an antisymmetry boundary condition has been selected. Interface roughness in this case is greater; the phenomenon has been studied by Partl (2006). It should be recalled that this work assumes a uniform shear stress distribution over the tire contact area.

\subsubsection{Longitudinal top-down cracking}

For the curved pavement section $(\mathrm{R}=10 \mathrm{~m})$, transverse strain $\varepsilon_{\mathrm{t}}$ at the top of the surface layer is recorded to be significant (see Fig. 5). The maximum strain $\varepsilon_{t}$ equals approximately $170 \mu$ strains (hence the surface layer lifetime is shorter than in the bottom layers due to vertical loading, Table 6), which provides an explanation why longitudinal top-down cracking can exist in curved pavement sections. Romanoschi (2001) had previously derived the exact same conclusion. 


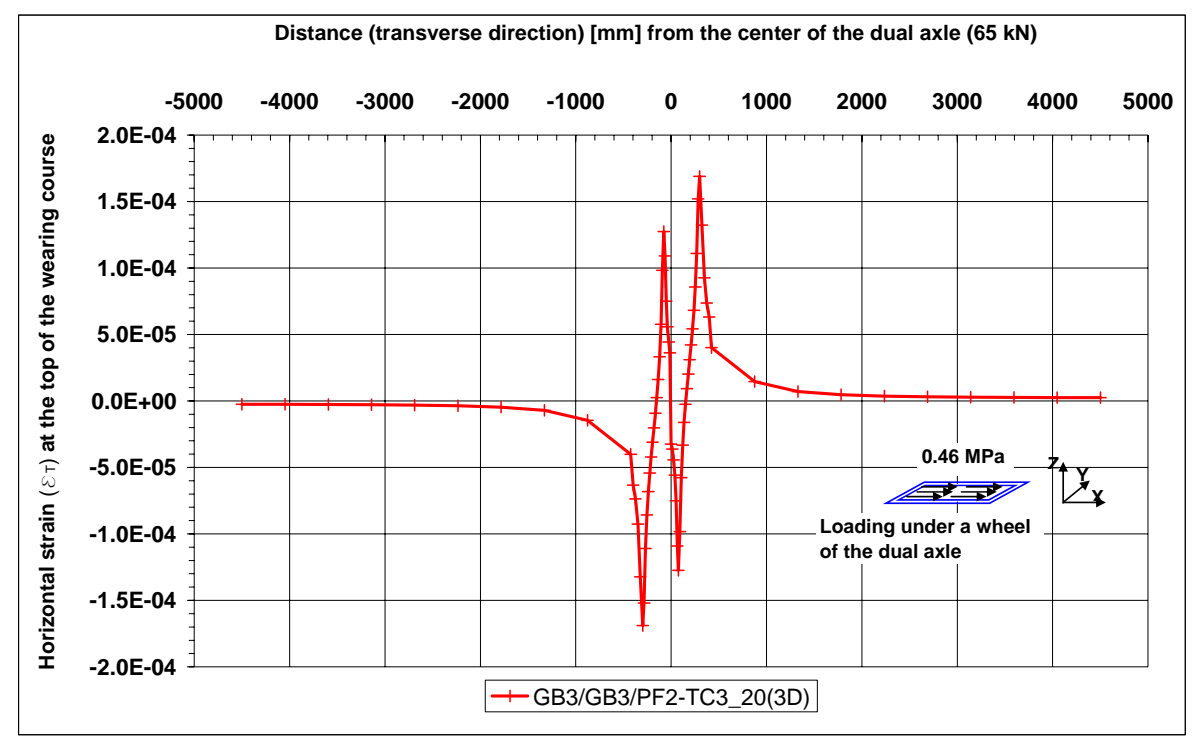

Figure 5: Transverse strain at the top of the surface layer

Let's now examine the shear fatigue interface more closely. The fatigue material parameters of the surface layer are given in Table 8.

Table 8: Material fatigue parameters of the HMA specimen referred to as BBSG

\begin{tabular}{|l|c|c|c|c|}
\hline Material & $\varepsilon_{6\left(10^{\circ} \mathrm{C}, 25 \mathrm{~Hz}\right)}$ & $E_{\left(10^{\circ} \mathrm{C}, 10 \mathrm{~Hz}\right)}$ & $E_{\left(15^{\circ} \mathrm{C}, 10 \mathrm{~Hz}\right)}$ & $\mathrm{b}$ \\
\hline BBSG & $150 \cdot 10^{-6}$ & $7,200 \cdot \mathrm{MPa}$ & $5,400 \cdot \mathrm{MPa}$ & -0.2 \\
\hline
\end{tabular}

In applying Equation (2) once again, a value is found for NEtc (where tc stands for top-down cracking) (see Table 9); this result offers the number of equivalent standard axles for initiating top-down cracking of the surface layer used to calculate NEtc. This measurement is rather straightforward because just the standard fatigue law from Equation (2) and stress field calculation due to horizontal loading are required. It should be recalled that only the risk coefficient $k_{r}$ is incorporated into the calculation of NEtc. Neither aging nor environmental degradation of the surface bitumen have been included.

If for the most flexible pavement, the top transverse strains (Table 9) and bottom longitudinal strains (Table 6) due to vertical loading were compared, it would be remarked that the top transverse strains are greater, by a factor of 1.45 over the bottom strains. On the other hand, for the most rigid pavement, the top transverse 
strains are about twice as high. The lifetimes derived for each asphalt material can also be compared according to the same benchmarks (Tables 6 and 9).

Table 9: Surface layer lifetime (NEtc) due to top-down fatigue cracking

\begin{tabular}{|c|c|c|c|}
\hline & \multicolumn{3}{|c|}{ With horizontal loading } \\
\hline Pavement structure & $\varepsilon_{\text {Tmax }}$ & $\mathrm{k}_{\mathrm{r}}$ & $\begin{array}{l}\text { Number of standard } \\
\text { axles (NEtc) }\end{array}$ \\
\hline GB3/GB3/PF2-TC3 20 & $169 \cdot 10^{-6}$ & 0.847 & $0.61 \cdot 10^{6}$ \\
\hline GB3/GB3/PF2-TC5 20 & $158 \cdot 10^{-6}$ & \multirow{2}{*}{0.743} & $0.57 \cdot 10^{6}$ \\
\hline GB3/GB3/PF2-TC5 30 & $154 \cdot 10^{-6}$ & & $0.65 \cdot 10^{6}$ \\
\hline
\end{tabular}

\subsubsection{Interface shear fatigue}

The effect of horizontal loading at the top of the surface layer yields a higher shear stress level at the interface. The calculation is performed here to determine whether the surface layer will debond earlier or later than the time required to reach full fatigue damage of the bottom asphalt layer (GB3).

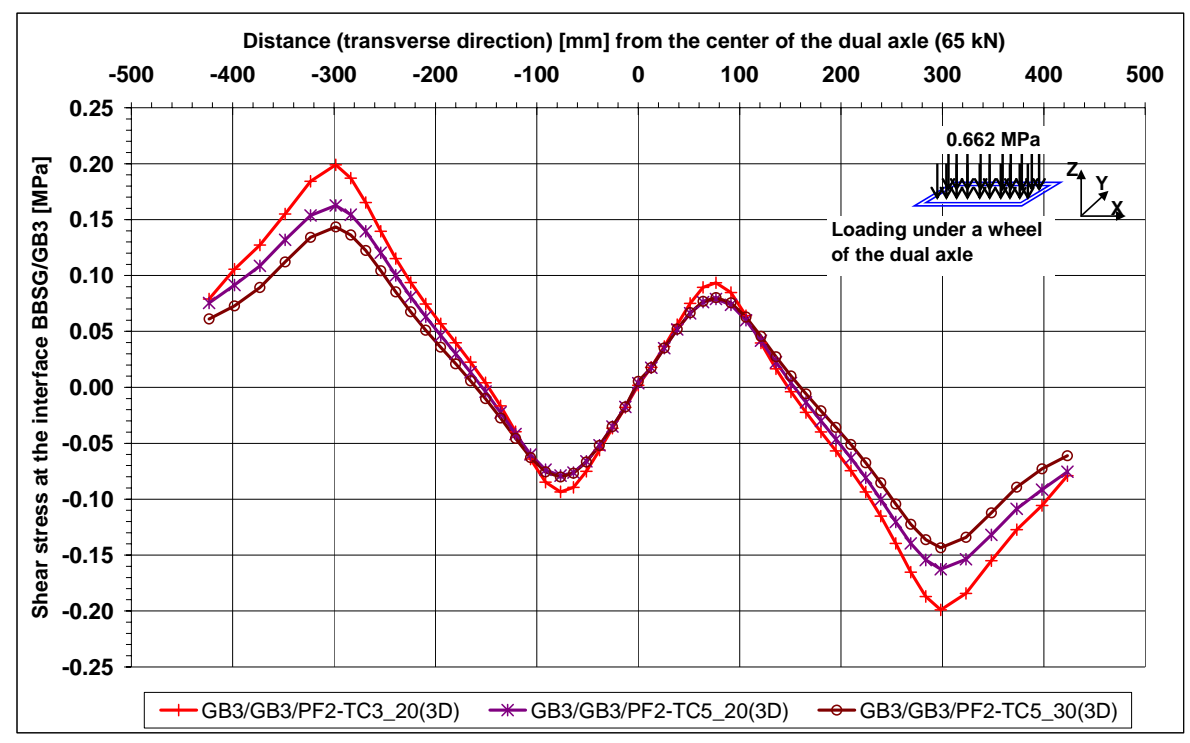

Figure 6a: Shear stresses at the (BBSG/GB3) interface due to vertical loading 


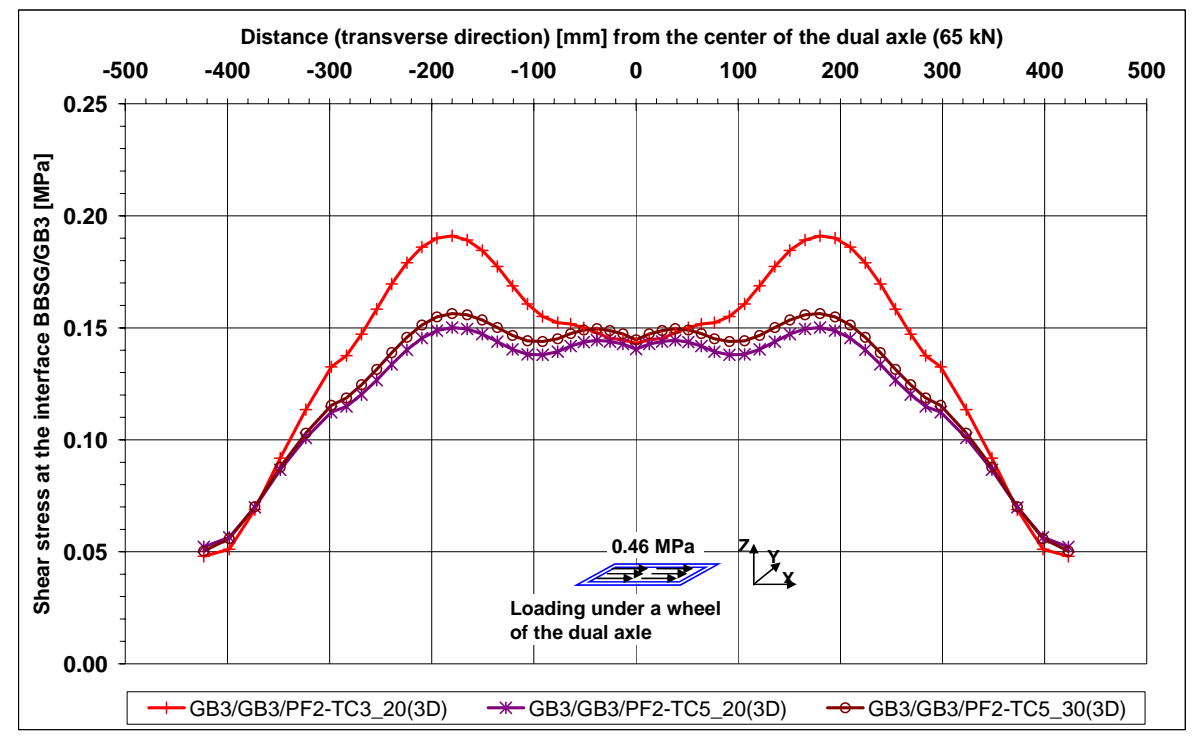

Figure 6b: Shear stresses at the (BBSG/GB3) interface due to horizontal loading

The maximum transverse tensile stress lies right at the edge of the standard dual axle towards the inside of the curved road. The outer side features transverse compressive stresses. Figure 6a clearly shows that the maximum interface shear stress is located right at the inside edge of the dual axle. The level of shear stress equals roughly 0.20 MPa with vertical loading. At this point, in adding a horizontal loading, a maximum of $0.20 \mathrm{MPa}$ is still obtained but this time located towards the middle of the inside wheel. On average, the level of shear stress is $100 \%$ more on a curved road section than on a straight section. It is easy to understand that the interface lifetime is greatly reduced and has the potential to become the main pavement failure mode. Once both loadings have been superimposed, the maximum shear stress can be calculated (Table 10); this maximum is located under the inside wheel close to its edge. Table 10 shows that interface lifetimes are nearly halved when taking horizontal loading into account.

Table 10: Effect of horizontal loading on the interface lifetime

\begin{tabular}{|l|c|c|c|c|c|}
\cline { 2 - 5 } \multicolumn{1}{l|}{} & \multicolumn{2}{|c|}{ without horizontal loading } & with horizontal loading & \multicolumn{1}{c|}{} \\
\hline Pavement structure & $\tau_{\max }$ & $\begin{array}{c}\text { Number of } \\
\text { standard } \\
\text { axles (NEi) }\end{array}$ & $\tau_{\max }$ & $\begin{array}{c}\text { Number of } \\
\text { standard } \\
\text { axles (NEi) }\end{array}$ & $\begin{array}{c}\text { Difference } \\
\text { between } \\
\text { NEi }\end{array}$ \\
\hline GB3/GB3/PF2-TC3 20 & $0.22 \mathrm{MPa}$ & $0.64 \cdot 10^{6}$ & $0.33 \mathrm{MPa}$ & $0.10 \cdot 10^{6}$ & $-84 \%$ \\
\hline GB3/GB3/PF2-TC5 20 & $0.18 \mathrm{MPa}$ & $0.88 \cdot 10^{6}$ & $0.28 \mathrm{MPa}$ & $0.12 \cdot 10^{6}$ & $-86 \%$ \\
\hline GB3/GB3/PF2-TC5 & $0.15 \mathrm{MPa}$ & $1.98 \cdot 10^{6}$ & $0.26 \mathrm{MPa}$ & $0.17 \cdot 10^{6}$ & $-92 \%$ \\
\hline
\end{tabular}


The computation reveals that interface lifetime may be greatly reduced with horizontal loading due to interface shear fatigue, in which case this failure mode can be considered as the first. This verification step must therefore be included in the pavement design method when in the presence of a shearing mode.

\subsubsection{Fatigue of the bottom layer}

The effect of horizontal loading on fatigue of the bottom layer will now be presented. Table 11 shows the maximum horizontal longitudinal strains $\varepsilon_{\text {Lmax }}$ (in the same direction as traffic) at the asphalt layer bottom. These maximum strains exceed the horizontal transverse strains (Diakhaté, 2007), which make them more important to fatigue lifetime. Once Equation (2) and Table 5 have been used, the values calculated indicate that horizontal loading does not really affect bottom layer lifetimes (Table 11).

Table 11: Effect of horizontal loading on fatigue of the bottom asphalt layer

\begin{tabular}{|c|c|c|c|c|c|}
\cline { 2 - 5 } \multicolumn{1}{c|}{} & \multicolumn{2}{|c|}{$\begin{array}{c}\text { Without horizontal } \\
\text { loading }\end{array}$} & \multicolumn{2}{c|}{$\begin{array}{c}\text { With horizontal } \\
\text { loading }\end{array}$} & \multicolumn{1}{c}{} \\
\hline Pavement structure & $\varepsilon_{\text {Lmax }}$ & $\begin{array}{c}\text { Number of } \\
\text { standard } \\
\text { axles (NEbc) }\end{array}$ & $\varepsilon_{\text {Lmax }}$ & $\begin{array}{c}\text { Number of } \\
\text { standard } \\
\text { axles (NEbc) }\end{array}$ & $\begin{array}{c}\text { Difference } \\
\text { between } \\
\text { NEbc }\end{array}$ \\
\hline GB3/GB3/PF2-TC3 20 & $123 \cdot 10^{-6}$ & $0.18 \cdot 10^{6}$ & $125 \cdot 10^{-6}$ & $0.17 \cdot 10^{6}$ & $-7.6 \%$ \\
\hline GB3/GB3/PF2-TC5 20 & $81.0 \cdot 10^{-6}$ & $0.77 \cdot 10^{6}$ & $81.4 \cdot 10^{-6}$ & $0.75 \cdot 10^{6}$ & $-2.3 \%$ \\
\hline GB3/GB3/PF2-TC5 30 & $62.0 \cdot 10^{-6}$ & $2.94 \cdot 10^{6}$ & $62.0 \cdot 10^{-6}$ & $2.94 \cdot 10^{6}$ & $0 \%$ \\
\hline
\end{tabular}

\subsubsection{Conclusions: Which failure mode?}

Table 12 summarizes the failure modes observed in the various cases, as a function of pavement rigidity. This table provides each lifetime calculated for each fatigue failure mode, i.e.: bottom layer fatigue (reflective cracking), top-down cracking, and interface fatigue (debonding). Each lifetime (shown in boldface) is in agreement with the $\mathrm{TCi}_{\mathrm{y}}$ Traffic Class obtained using the current French standard pavement design code (LCPC, 1998).

For the first pavement structure (i.e. GB3/GB3/PF2-TC3 ${ }_{20}$ ), each damage mode appears at approximately the same time, meaning that in this case both top-down cracking and interface design do not input anything new. In Figure 7, the Traffic Class is represented, and it is observed that bottom and interface fatigue computations lead to the same solution for the most flexible pavement. On the other hand, GB3/GB3/PF2-TC5 ${ }_{20}$ and GB3/GB3/PF2-TC5 ${ }_{30}$ are pavement structures with thicker asphalt layers and hence higher rigidities; for their case, each computed failure mode is sharply distinct. 
Table 12: Lifetimes of each pavement structure under different failure modes

\begin{tabular}{|c|c|c|c|c|}
\hline & $\begin{array}{l}\text { Bottom fatigue } \\
\text { (transverse } \\
\text { reflective cracks) }\end{array}$ & $\begin{array}{c}\text { Top fatigue } \\
\text { (longitudinal top- } \\
\text { down cracks) }\end{array}$ & $\begin{array}{l}\text { Interface } \\
\text { fatigue } \\
\text { (debonding) }\end{array}$ & \\
\hline Pavement structure & $\begin{array}{c}\text { Number of } \\
\text { standard axles } \\
\text { (NEbc) }\end{array}$ & \begin{tabular}{|c|} 
Number of \\
standard axles \\
(NEtc)
\end{tabular} & $\begin{array}{l}\text { Number of } \\
\text { standard } \\
\text { axles (NEi) }\end{array}$ & \\
\hline GB3/GB3/PF2-TC3 20 & $\begin{array}{l}\mathbf{0 . 1 7}^{6} \mathbf{1 0}^{6} \\
\left(\mathrm{TC} 2_{20}\right)\end{array}$ & $\begin{array}{l}0.61 \cdot 10^{6} \\
\left(\text { TC }_{20}\right)\end{array}$ & $\begin{array}{l}\mathbf{0 . 1 0} \cdot \mathbf{1 0}^{\mathbf{6}} \\
\left(\mathrm{TC} 2_{20}\right)\end{array}$ & $\begin{array}{c}\text { Interface and } \\
\text { bottom }\end{array}$ \\
\hline GB3/GB3/PF2-TC5 20 & $\begin{array}{l}\mathbf{0 . 7 5 \cdot 1 0 ^ { 6 }} \\
\left(\mathrm{TC}_{20}\right)\end{array}$ & $\begin{array}{l}0.57 \cdot 10^{6} \\
\left(\mathrm{TC}_{20}\right)\end{array}$ & $\begin{array}{l}0.12 \cdot 10^{6} \\
\left(\mathrm{TC}_{20}\right)\end{array}$ & Interface \\
\hline GB3/GB3/PF2-TC5 30 & $\begin{array}{l}\mathbf{2 . 9 4 \cdot 1 0 ^ { 6 }} \\
\left(\mathrm{TC4}_{30}\right)\end{array}$ & $\begin{array}{l}0.65 \cdot 10^{6} \\
\left(\mathrm{TC} 2_{30}\right)\end{array}$ & $\begin{array}{l}0.17 \cdot 10^{6} \\
\left(\mathrm{TC}_{30}\right)\end{array}$ & $\begin{array}{c}\text { Interface and } \\
\text { top-down }\end{array}$ \\
\hline
\end{tabular}

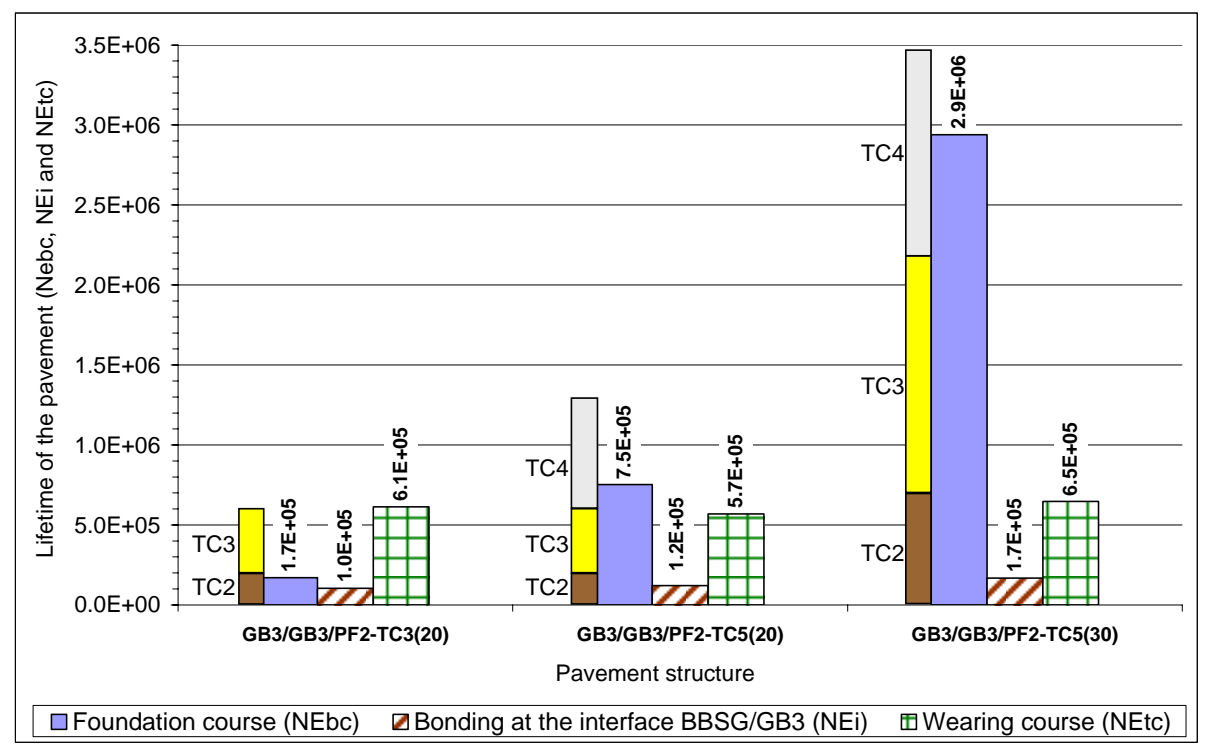

Figure 7: Representation of pavement failure mode lifetimes (NE) and traffic class

For both these structures, it is evident that bottom cracking appears later than either top-down or interface cracking. Practically speaking, the pavements have been designed (with the bottom cracking criterion) for 20 and 30 years, respectively, given that a TC5 traffic class can, in curved road sections, lead to shorter lifetimes. The "GB3/GB3/PF2-TC5 ${ }_{20}$ " structure can experience interface debonding after just 3-4 years and top-down cracking after 15 years, as opposed to 20 years for wearing course cracking. For the "GB3/GB3/PF2-TC5 30 " rigid pavement, these differences are greater and interface cracking begins after only 2 years, top-down cracking after 
7 years, and 30 years for bottom cracking. These findings mean that top-down and interface cracking must be included in pavement design whenever horizontal loading is present, as is the case in all curved road sections.

\section{Conclusion and outlook}

This work has demonstrated the increasing need to introduce interface fatigue into pavement design whenever thin surface layers are being used. Pavement manufacturers must focus more heavily on tack coat and interface bonding performance when such performance constitutes the primary damage mode. In this paper, an application to standard pavement has been completed and the observation could be drawn that in curved pavement sections, both surface layer performance and interface performance must be improved. A design method associated with the interface shear test (Diakhaté, 2007) has been proposed herein. Pavement damage observations in the field, recently coupled with pavement interface damage modeling, indicate that greater emphasis needs to be placed on identifying interface fatigue performance. (Diakhaté, 2008), with the work by Romanoschi (2001) providing the first fatigue results. In this paper, data from Diakhaté (2007) were used. Other experimental results on interface shear performance have been introduced (but for the most part not specific to fatigue), and these can contribute to improving techniques as well. The example chosen herein for three different pavement structures (in terms of rigidity and thickness) numerically shows that pavement interface design becomes a required step mainly for situations of high traffic volumes and either rigid or semi-rigid pavements. Tack coat and interface fatigue performance is especially important in these situations for curved pavement sections exposed to a significant horizontal loading. The Rilem Task Group (TG4) involved in the work of the Technical Committee on Advanced Testing in Binders is also able to contribute experimental data. In reality, the early degradation of surface layers and their interfaces does not affect wearing layer capacity. This pavement design method therefore needs to be implemented for both surface layers and bonding performance in the presence of horizontal loadings.

\section{References}

Burmister D.M., “The general Theory of Stresses and Displacements in Layered Systems”, Journal of Applied Physics, Volume 16, Issue 2, 1945, p. 89-94.

Canestrari F., Ferrotti G., Partl M. N. Santagata E., “Advanced testing and characterization of interlayer shear resistance”, In 84 $4^{\text {th }}$ TRB annual meeting, 9-13 January 2005, p. 1-26.

Caron J.F., Diaz Diaz A., Carreira R.P., Chabot A., Erlhacher A., "Multi-particle modelling for prediction of delamination in multi-layered materials", Composites Sciences and technology, Volume 66, Issue 6, May 2006, p. 755- 765. 
Diakhaté M., Petit C., Millien A., Phelipot-Mardelé A., Pouteau B., Goacolou H. "Comparison of direct shear and torque tests for determining viscoelastic shear behaviour of tack coats", Proceedings of the International Conference on advanced characterization of pavement and soil engineering materials, 20-22 June 2007, Athens (Greece).

Diakhaté M., Petit C., Millien A., Phelipot-Mardelé A., Pouteau B., Goacolou H., “Interface fatigue cracking in multilayered pavements: Experimental analysis”, Proceedings of the $6^{\text {th }}$ International Conference on cracking in pavement, 16-18 June 2008, Chicago (USA), CRC Press/Balkema.

Granju J-L., Sabathier V., Turatsinze A., Toumi A., "Interface between an old concrete and a bonded overlay: debonding mechanism”, Interface science, Vol. 12, № 4, 2004, p. 381388.

LCPC, SETRA. Catalogue des structures types de chaussées neuves, 1998, ISSN 1151-1516.

LCPC, SETRA. Guide de conception des chaussées neuves, 1998.

Partl M.N., Canestrari F., Ferrotti G., Santagata F. A., "Influence of contact surface roughness on interlayer shear resistance”, In $10^{\text {th }}$ International Conference on Asphalt Pavements, ISAP, Quebec, August 2006.

Pouteau B., Diakhaté M., Petit C., “Tack Coat Performance - Toward a Design Method?”, In 4th Eurasphalt \& Eurobitume Congress, Copenhagen, Denmark, May, 21-23, 2008, 9 p.

Romanoschi S. A., Metcalf J.B., "Effects of Interface Condition and Horizontal Wheel Loads on the Life of Flexible Pavement Structures", Transportation Research Board of the National Academies, Vol. 1778, 2001, p.123-131, ISSN 0361-1981.

Romanoschi S. A., Metcalf J.B., "Characterization of Asphalt Concrete Layer Interface", Transportation Research Board of the National Academies, Vol. 1778, 2001, p.132-139, ISSN 0361-1981.

Tran Q. T., Toumi A., Granju J.-L., "Experimental and numerical investigation of the debonding interface between an old concrete and an overlay", Materials and Structures, Vol. 39; N 3, 2006, p. 379-389.

Cast3M, “http://www-cast3m.cea.fr/cast3m/xmlpage.do?name=documentation”, 2003 